\title{
The filter-loading effect by ambient aerosols in filter absorption photometers depends on the coating of the sampled particles
}

\section{Luka Drinovec et al.}

Correspondence to: Luka Drinovec (luka.drinovec@aerosol.si) and Griša Močnik (grisa.mocnik@aerosol.eu)

The copyright of individual parts of the supplement might differ from the CC-BY 3.0 licence. 


\section{S.1 Filter-loading effect during intensive campaigns in Paris and Payerne}

Filter-loading effect parameter $k$ was measured during the Paris and Payerne EMEP campaigns (summer 2012, winter 2013) using the Aethalometer model AE33 (Figure S1). Its biggest variation occurs for the long wavelength channels $(6 \& 7,880 \mathrm{~nm}$ and $950 \mathrm{~nm}$ ). There are some short-term variations and some longer stable periods which can last for several days (see Figure S1).
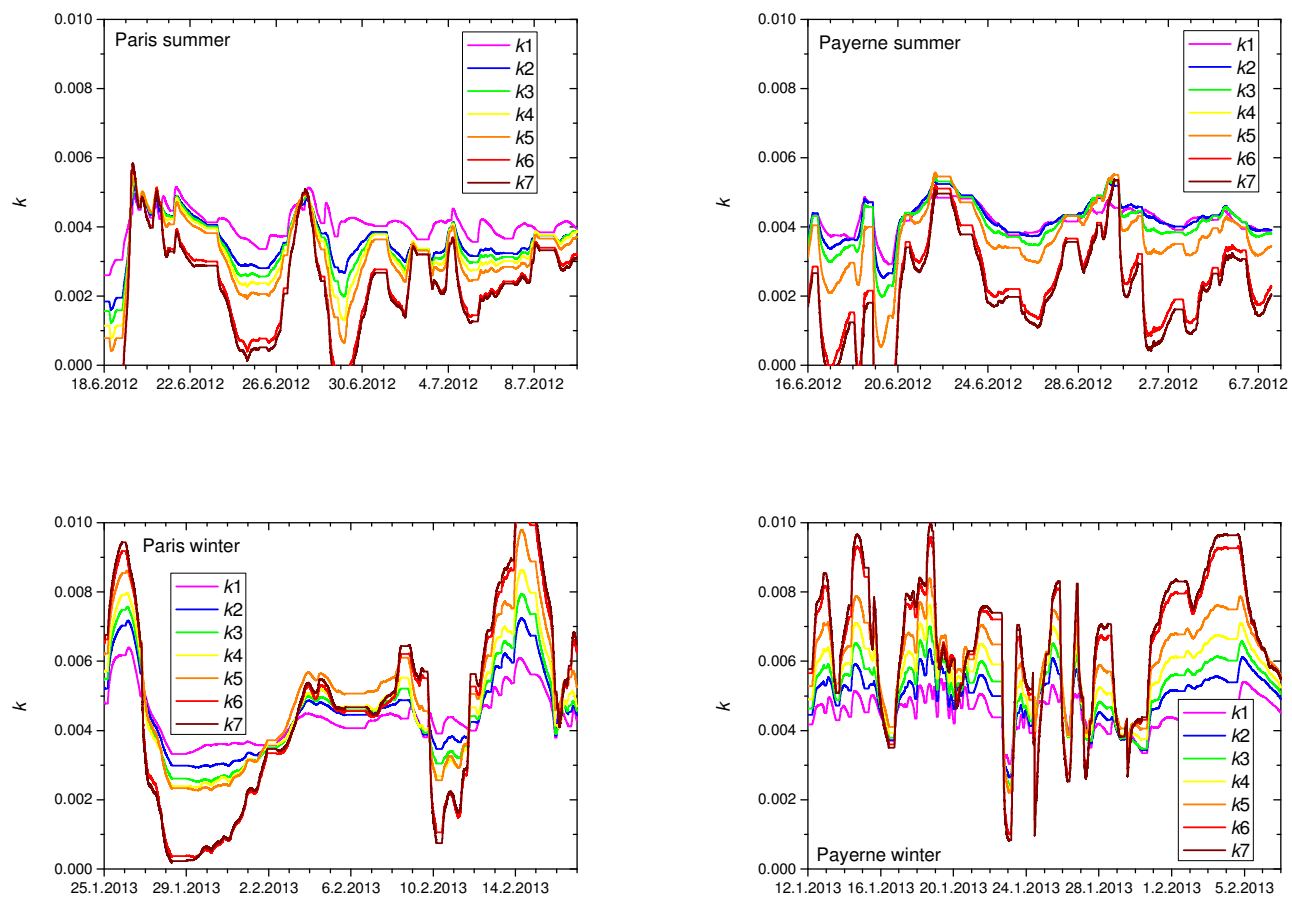

Figure S1: Time series of filter-loading effect parameter $k$ as measured by the Aethalometer model AE33 during the EMEP campaigns in Paris and Payerne. 


\section{S.2 Mixing state during intensive campaigns in Paris}

The particle mobility diameter in Paris was measured using a TSI SMPS with Electrostatic classifier model 3081 and Condensation particle counter model 3775. The peak position (Mode) of the particle number size distribution was determined using TSI Aerosol Instrument Manager software. During summer, there is an evident increase of the particle size with increasing coating factor, which indicates that the aerosols are internally mixed. During winter, there is an increase of particle size with $C F<12$; for bigger coating factors, the particle size does not increase as expected for externally mixed aerosols.
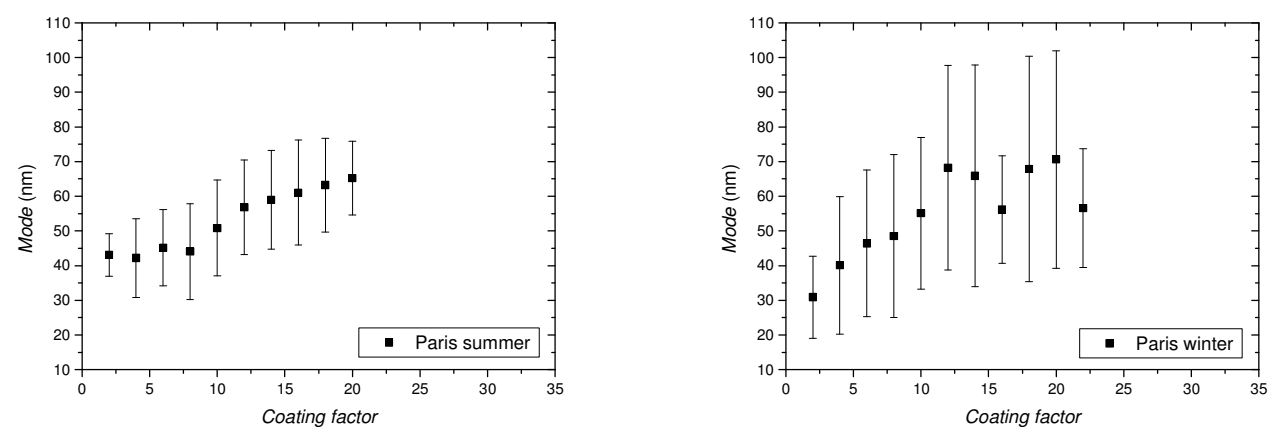

Figure S2: Peak position (Mode) of the number size distribution during the intensive campaigns in Paris.

Hourly data are averaged into coating factor $(C F)$ bins of 2 units wide. The error bars represent the standard deviation for data points inside each bin. 


\section{S.3 Effect of thermo-denuder on particle size distribution}

40

The effect of the thermo-denuder was evaluated for the ambient sample from Ljubljana, before the campaign (Figure S3). With the thermo-denuder switched on, we measured the peak of the number size distribution at 60 $\mathrm{nm}$. The particle number dropped for particles larger than $200 \mathrm{~nm}$ in mobility diameter. The thermo-denuder heated to $300^{\circ} \mathrm{C}$ caused a reduction of particle size, which is most evident for particles larger than $100 \mathrm{~nm}$.

45 There is an increase in particle number smaller than $30 \mathrm{~nm}$ when the denuder is switched on compared to when it is switched off. The total particle number was reduced by $40 \%$.

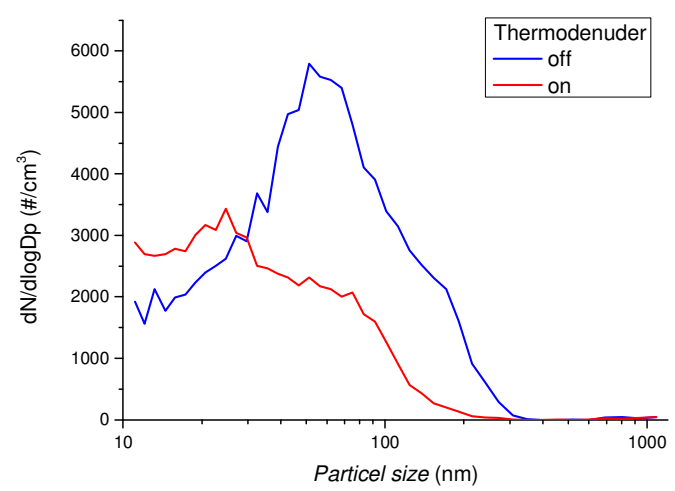

Figure S3: Particle size number distribution for ambient aerosols in Ljubljana with the thermodenuder turned off and on $\left(300^{\circ} \mathrm{C}\right)$. 

sampling

$29^{\text {th }}$ August 2014 was selected as a typical Ljubljana campaign day because of the stable sunny weather conditions. Scanning electron microscopy (SEM) samples were obtained in the middle of the afternoon when the black carbon concentration was reduced due to vertical mixing (Figure S4, A): an ambient sample was taken at $15 \mathrm{~h}$ (red dashed line), a thermo-denuded sample at 16h (green dashed line). The particle size distribution showed fresh emissions in the early morning and evening with mean particle size of approximately $50 \mathrm{~nm}$ (Figure S4, B). During the afternoon, larger particles with the peak above $100 \mathrm{~nm}$ are measured (Figure S4, C). Impactor stage 4 (with a size range of $170-260 \mathrm{~nm}$ ) samples were analyzed in the main part of the article.

60

A

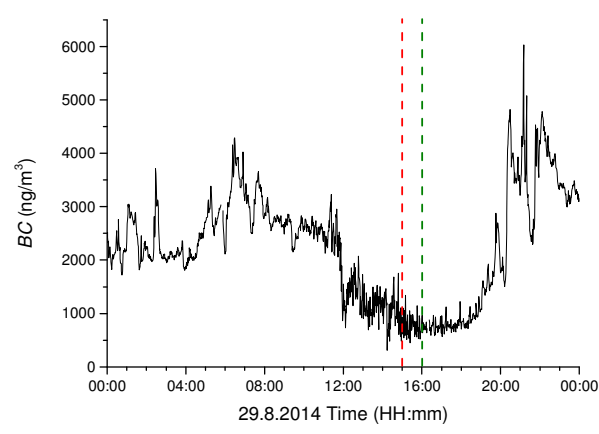

$\mathrm{C}$

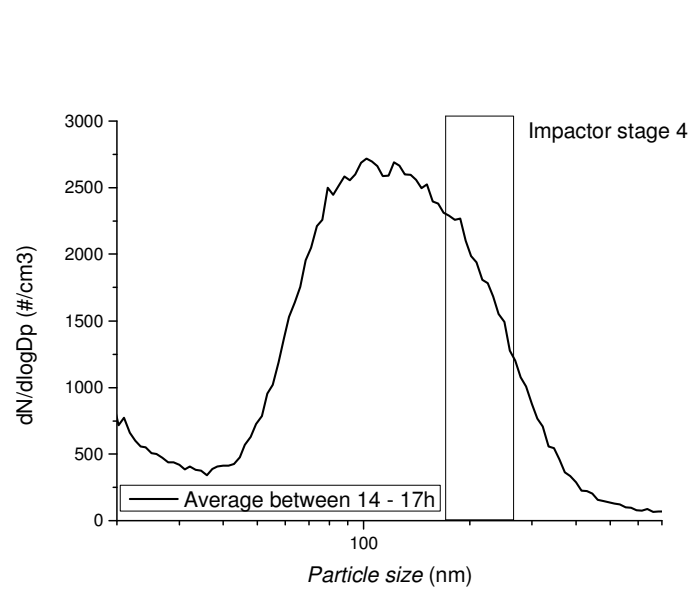
列
B

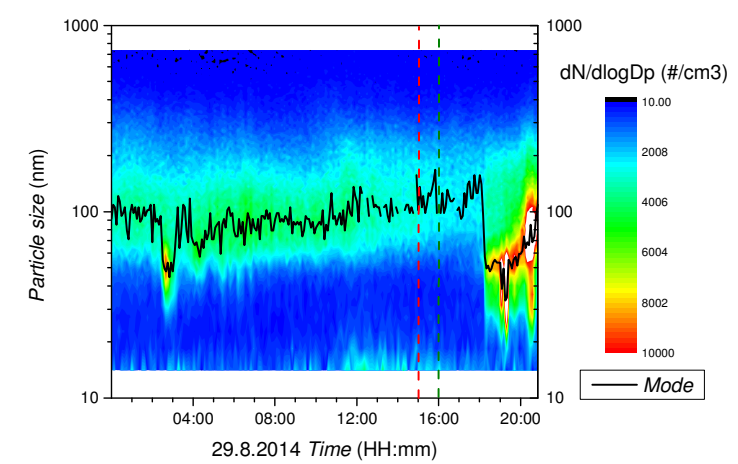

Figure S4: Measurements of black carbon mass concentration (panel A) and particle size distribution (panel B) for 29 August 2014 are presented. Red and green dashed lines represent sampling times for the ambient and thermo-denuded sample. Panel $\mathrm{C}$ shows the average particle size distribution between 14 $17 \mathrm{~h}$ and the estimated size of the particles collected on impactor stage 4. 
Figure S5 shows the dependency between the filter-loading parameter $k_{6}$ and the absorption Ångström exponent for the monthly averages listed in Table 2 .

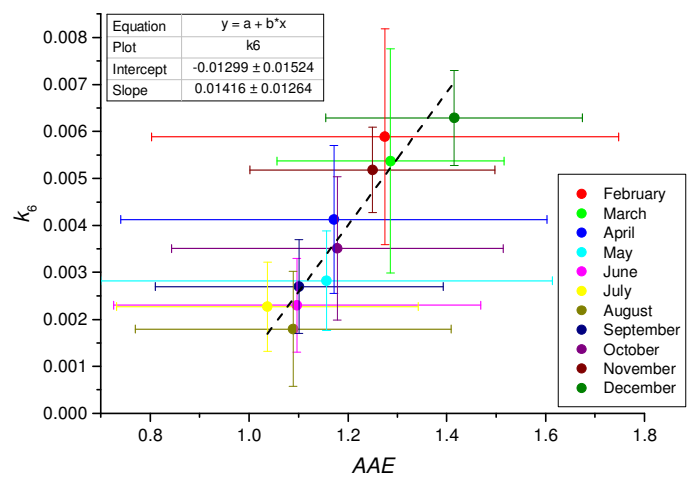

Figure S5. Correlation between the FLE compensation parameter $k_{6}$ and the absorption Ångström exponent $A A E$ for the monthly average values and standard deviation obtained during the 2013 Paris campaign (SIRTA observatory).

\section{S.6 Reno experiment $B C$ time series}

Figure S6 shows the time series for the mustard oil lamp and flaming needles emission measurements. For the mustard oil lamp it was possible to continuously inject diluted emissions into the distribution chamber. For the flaming needles experiment, the flaming emissions were injected into the distribution chamber. When air was drawn into the instruments, the aerosol concentrations decreased exponentially.

A

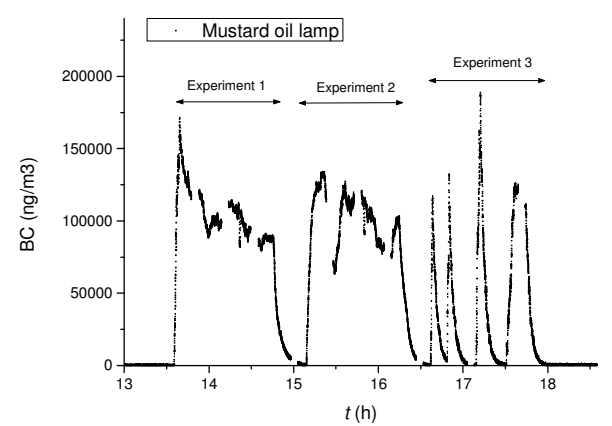

B

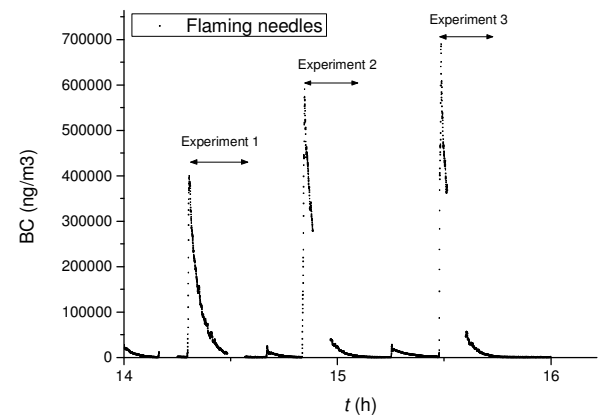

Figure S6. Time series of $B C$ during the Reno laboratory experiments for the mustard oil lamp (A) and flaming needles (B) emission measurements. 